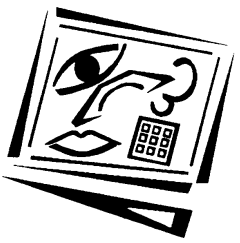

\title{
"But they won't come to lectures ..." The impact of audio recorded lectures on student experience and attendance
}

\author{
Helen E. Larkin \\ Deakin University
}

\begin{abstract}
The move to increasingly flexible platforms for student learning and experience through provision of online lecture recordings is often interpreted by educators as students viewing attendance at lectures as optional. The trend toward the use of this technology is often met with resistance from some academic staff who argue that student attendance will decline. This study aimed to explore students' use of online lectures and to measure the impact of them on student attendance at lectures. A pre and post evaluation methodology was undertaken using a self administered questionnaire that gathered both quantitative and qualitative data. Overall attendance was recorded at each lecture throughout the semester. Results indicated that attendance remained high throughout the semester and while only a minority of students used the recordings, those who did found them to be helpful. Most students used them to either supplement their learning or to make up for a lecture that they had not been able to attend. This study provides evidence that contrary to popular belief, Generation Y students in general, do not aspire to replace lectures with downloadable, online versions. Many of the students in this study valued the opportunity for interactive learning provided by face to face teaching. Finally, a model that outlines the attributes that contribute to quality teaching is used to describe how this technology can contribute to positive student experiences and can enhance reflective teaching practice.
\end{abstract}

\section{Introduction}

Online educational technologies have gained acceptance as an integral part of providing flexible education environments that address the diverse needs of students in higher education. The degree to which these technologies are embraced by both teaching staff and students varies across units, programs and universities. To a generation of students who reportedly are multi-taskers managing multiple priorities of which study is only one; are said to be more technologically savvy than their teachers; have more difficulty communicating in traditional ways; and, have an expectation of 24 hour access to all services including educational services, online teaching is often promoted as the answer to this generations' demands (Arhin \& Cormier, 2007; Nimon, 2007; Pardue \& Morgan, 2008; Pendergast, 2007; Skiba, 2005). McGarr (2009) also argues that proponents of this type of teaching technology claim that it facilitates students' mobile learning and can also enhance the student experience. Recent studies, however, challenge the assumption that this generation of higher education students are uniform in their technological competence and argue that instead they are skilled in core technologies such as mobile phones, social networking and email but that their comfort with other, more specialised communication technologies shows considerable variation (Kennedy, Dalgarno, 
Bennett, Judd, Gray \& Chang, 2008; Kennedy, Judd, Churchward \& Gray, 2008). Thus, competence or otherwise in relation to technology specifically, cannot necessarily be explained through generational attributes alone.

Through online environments such as BlackBoard and WebCT, the capacity to download lectures is becoming common place, regardless of mode of study. This technology is being increasingly used to provide students with electronic capture of face to face lectures, for substitutional purposes or as supplementary learning material (McGarr, 2009; von Konsky, Ivins \& Gribble, 2009).

Anecdotally, a common response by staff to demands or requests to incorporate these online approaches into their teaching and learning technologies, is a concern that if recorded lectures are made available, students will opt out of attending lectures. A large scale study by Gosper, Green, McNeill, Phillips, Preston and Woo (2008) confirmed this is a common concern amongst teaching staff in Australian universities. It could be argued that this concern reflects a 'Level 1' theory of teaching as described by Biggs and Tang (2007), that views teaching as purely the transmission of knowledge and a lecture as merely the vehicle for delivering information. This 'sage on the stage' perspective supports a flawed belief that "the fundamental problems in the quality of university education can be solved by transferring knowledge more efficiently, using some form of information technology" (Ramsden, 2003, p. 108).

As discussed by Ramsden (2003) and others, these views don't recognise the interactive nature of face to face teaching and a need to focus on what the student does and needs to know that is consistent with contemporary views of teaching, outlined for example by Biggs and Tang (2007). As discussed by McGarr (2009), the often passive role ascribed to students in lectures is contrary to these contemporary views. While both critics and supporters of lectures continue to argue their relative advantages and disadvantages, the traditional lecture continues to be a dominant method for the delivery of teaching and learning in higher education (McGarr, 2009; Williams \& Fardon, 2007). Several authors (McGarr, 2009; Taylor, 2009; Lazzari \& Betella as cited in McGarr, 2009) argue the need to investigate the impact of lecture recordings on lecture attendance specifically, and teaching and learning in general. As described by McGarr (2009) "questions linger in relation to its true educational value, the ways it can best be utilised to support teaching and learning, and its affect on attendance and student engagement" (p. 312). This question is addressed in an Australian study by von Konsky, Ivins and Gribble (2009) who found that the act of making lectures available online did not have a significant impact on student attendance at lectures. This study recorded week by week attendance at lectures, the frequency of downloading of lectures and student perceptions of their use.

Kennedy et al. (2008) called for the use of existing and emerging technological advances to be adopted not on the basis that they are readily and easily accessible but on sound pedagogical principles. Evidence as to their use needs to drive policy and practice and there has been some research around this question in recent times. A study by Copley (2007) at the University of Southampton in the United Kingdom evaluated the use of audio and video recordings of lectures, made available via Blackboard. Results indicated student enthusiasm for this technology with a high level of uptake ranging from $61 \%$ to $81 \%$ of students overall making use of these resources. Students most commonly indicated that their reasons for downloading online lecture material were for revision purposes and preparation of assessment tasks. However, in 
this study lecture attendance was not directly recorded, depending instead on student responses in which $12 \%$ of students reported that availability of online lectures may cause them not to attend lectures.

An Australian study reported in 2007 by Lee and Chan, explored the use of podcasts as a means of providing supplementary learning material. This study with 18 respondents found a high level of uptake of the technology but that students generally preferred listening to the recordings using a computer at home rather than downloading onto a portable device for mobile learning purposes. Another Australian study by Williams and Fardon (2007) found that $79.6 \%$ of students reported that they continued to 'always' or 'regularly' attend lectures even though online recorded lectures were available either in streamed or downloadable versions. This study also found that most students used the recordings for review and revision purposes. Neither of these Australian studies explored the actual impact on lecture attendance. The study by Gosper et al. (2008) extensively explored the use of web based lecture technologies in four Australian universities, including student self-reported attendance at lectures. However, this study explicitly did not canvass the views or experiences of students who did not make use of online lecture recordings.

Two USA studies (Bongey, Cizadlo \& Kalnbach, 2006; Hove \& Corcoran, 2008) specifically set out to investigate impact on student attendance at lectures as well the impact on student experience and perceptions of impact on learning. Indeed, Hove and Corcoran commented on a lack of research evidence regarding the question of the level of absenteeism associated with availability of online lecture recordings. Both studies found that availability of this technology did not lead to a corresponding decline in attendance and they supported students' use of online lecture recordings to support and supplement student learning rather than replacing face to face teaching. However, both studies recommended that further research was required.

The study outlined in this paper aimed to explore, in an Australian context, students' views of the use of online recorded lectures and to directly measure the impact of this technology on student attendance at lectures. The research specifically sought to include the experiences of the whole student cohort regardless of actual use or otherwise of the online lectures. The study was carried out with third year, undergraduate occupational therapy students who were undertaking a unit with a previously high level of student attendance at lectures. The study also aimed to further our understanding of how the provision of this teaching activity may contribute to quality teaching and learning more broadly. The broader question guiding this research was: 'Does recording of lectures add value to the student experience, instead of merely being used as a panacea for what are often broader based issues such as lack of teaching space and increasingly demanding students with increasingly diverse needs?'

\section{A model of teaching excellence}

Given the call for evaluation of these online teaching technologies, in the context of what makes for good teaching, it is useful to consider the factors that describe sound pedagogical principles. Kane, Sandretto and Heath (2004) described the general characteristics of excellent teachers as: having a command of the subject matter; being enthusiastic; communicating their subject matter clearly; and, being well prepared and organised. However, issues in relation to student experience are also acknowledged by 
Kane et al. as being important. These include the need for teachers to have a respect for and interest in students, to regularly monitor student learning and gain regular formal and informal feedback from students.

Through their own research, Kane et al. (2004) developed a hub and spoke model describing the common attributes of excellent university teachers. The characteristics included the teacher's subject knowledge; their skills in being able to make real world connections and relating what they know to what students know; their interpersonal relationships with students; the research/ teaching nexus that they bring to the classroom; and finally, their personality. This latter characteristic discussed the need for teachers to "exhibit much of their own personality" (p. 298) and to display a sense of humour and a sense of enjoyment of the whole academic experience. The hub of this model is reflective practice where excellent teachers engage in regular reflection on their teaching practice and regularly adopt strategies to do this. This includes reflecting on the technical aspects of teaching such as practical teaching skills and critical reflection about the impact of one's actions on the experience of students.

This model reinforces the need for educators to evaluate and reflect upon new teaching techniques and technologies as they become available. As previously stated, new initiatives and practices need to be accompanied by evidence of a sound pedagogical basis. This study describes the formal evaluation of the first-time introduction of recorded lectures and the impact of this technology both on students' experience and also on their attendance at lectures. The model by Kane et al. (2004) was used to frame this research and to reflect on the findings.

\section{Study aims}

The overall aims of the study were to investigate the impact of recorded lectures on attendance at lectures and to explore the experience of students who used this technology. Specifically, the aims of the study were to explore the students' previous use of recorded lectures; to explore students' uptake and use of online recorded lectures; and, to measure level of attendance at lectures throughout the semester.

\section{Method}

The study was undertaken in semester one at Deakin University, Geelong in 2008 and approved by the Human Ethics Office, Deakin University. The unit in question was a third year, undergraduate, occupational therapy unit with an on campus enrolment at the beginning of semester of 64 students. The unit was conducted over the 13 week semester as a one-hour lecture, followed by a two-hour tutorial at a later time but on the same day.

The study collected quantitative and qualitative data through a questionnaire administered at the beginning of week one and a follow up questionnaire administered in week 13. A head count of students was undertaken each week within the lecture. All lectures throughout the semester were recorded as they were being presented, using a digital, portable recorder. They were uploaded immediately at the end of the lecture onto Blackboard, the university's learning management system. Lectures only were recorded - no recordings of discussions within tutorials were made. Audio recordings were chosen as the technology of choice, as the available lecture facility did not have audio and video recording capacity. However, lecture note presentation slides were available electronically in conjunction with the recorded 
lectures so that students had the opportunity to refer to the lecture presentation at the same time as listening to the lecture recordings.

In the first questionnaire, students were asked to provide information about their previous and typical patterns of attendance at lectures in the past, whether they had previously used recorded lectures and how useful they found them to be. At the conclusion of the semester, the second questionnaire asked students about their actual attendance, whether they had used the lecture recordings, for what purpose and how useful they considered them to be.

\section{Results}

\section{Response rate}

Of the 64 students who were enrolled in the unit at the beginning of semester, 58 (91\%) students completed the first questionnaire. The majority of respondents were female with 6 students $(10.3 \%)$ being male. Refer to Table 1 for details regarding age of respondents.

Table 1: Age of respondents

\begin{tabular}{|l|c|c|}
\hline \multicolumn{1}{|c|}{ Age range } & No. of students & Percent \\
\hline 20 years or less & 32 & 55.2 \\
\hline 21 years & 11 & 19 \\
\hline 22-25 years & 11 & 19 \\
\hline 26-29 years & 3 & 5.1 \\
\hline 30 years or more & 1 & 1.7 \\
\hline Total & 58 & 100 \\
\hline
\end{tabular}

Table 1 shows that $93 \%$ of those students who participated in the study fall into the category of Generation Y, as defined by Pendergast (2007), that is, they were born in the decades 1982-2002. The second questionnaire was completed by 49 (78\%) of the 63 students (one student having withdrawn during the semester).

\section{Results of questionnaire one (beginning of semester)}

Students described themselves initially as the sort of student who:

- Attends lectures only if relevant to an assessment task (5\%);

- Attends, dependent on social and work commitments (12\%);

- Attends most lectures unless sick or urgent family needs arise $(66 \%)$;

- Attends based on their view of the quality of the teacher / lecturer concerned $(15 \%)$; or,

- Attends if the gap between the lecture and the tutorial is not too great (2\%).

This was, therefore, a group of students who perceived themselves as attending most lectures. When asked how often they had previously used recorded lectures, $83 \%$ of students reported they had used this technology previously. Of this group, 58\% reported they used recordings when they had been unable to attend a lecture, while $35 \%$ of students used them to supplement their learning. Qualitative comments from students, collected as part of the first questionnaire, confirm these findings. 
It was great when you missed the lecture as sometimes only reading lecture notes doesn't give much insight into what was discussed.

Can go back over the details that I may have missed or if I wasn't able to attend lectures to see if there was anything not on the notes.

Another $4 \%$ of students used lecture recordings due to a specific health condition or disability while $6 \%$ reported that they always intended to use them but never quite got around to it. Of those students with previous experience, $85 \%$ listened to them through Blackboard, while $15 \%$ downloaded them onto a personal, audio device. More than half (57\%) of students reported that they preferred recordings to be made of real time lectures; $14 \%$ of students preferred recordings to be made separately and in isolation of the actual lecture, while $29 \%$ were not concerned one way or the other.

Despite the age profile of the student group, a number of students expressed views contrary to those commonly attributed to this generation. Many students expressed a preference for not using recorded lectures to replace face to face teaching and were not always comfortable with technology.

I find if the lecturer is interesting and has a passion for the content, I am more likely to attend and put in the hard yards.

I didn't make use of them because I wasn't sure how to (I'm not really good with computers) and not sure what equipment I needed.

Please stop trying to replace student/lecturer contact. Besides struggling away at home, it makes social stuff a struggle.

There is a significant decrease in attendance when lectures are recorded and therefore less questions were asked so learning opportunities and student interaction was decreased.

iLectures are helpful but not my preference for learning as they do not suit my learning style.

As a result of these concerns, the unit coordinator reassured students in week one, that face to face teaching time would not be lost or reduced as a result of lectures being recorded and available for download.

\section{Student attendance}

The actual recorded student attendance (as measured by a simple head count) at lectures over a 13 week semester, ranged from a low of $75 \%$ attendance to a high of $95 \%$ attendance with an overall mean attendance of $84 \%$.

\section{Result of questionnaire two (end of semester)}

At the end of semester, 46 (94\%) students reported that they had "attended most if not all lectures except in cases of sickness or urgent family need". This is consistent with the actual attendance as measured by head count, given a certain percentage of students who experience sickness or family hardship over the course of a semester.

Students were asked on a scale of 1-5 with 1 being Never to 5 being All the time, how often they used the audio recordings in this particular unit. Students were advised that this frequency related to the number of recordings downloaded over the course of the 
semester and not the number of times they may listen to a specific lecture recording. Results are contained in Table 2.

Table 2: Frequency of reported use

\begin{tabular}{|l|c|c|}
\hline \multicolumn{1}{|c|}{ Frequency of use } & No. of students & Percent \\
\hline 1 (Never) & 27 & 55.1 \\
\hline 2 & 16 & 32.7 \\
\hline 3 & 6 & 12.2 \\
\hline 4 & 0 & 0 \\
\hline 5 (All the time) & 0 & 0 \\
\hline Total & 49 & 100 \\
\hline
\end{tabular}

With a mean frequency of use of 1.6, the figures in Table 2 show that less than half the student group downloaded the lecture recordings infrequently, at most. Of those students who did, $36 \%$ reported that they did so when unable to attend a lecture while $50 \%$ used them to supplement their learning. Table 3 presents the data in relation to how useful the 22 students who had used them found them to be; on a scale of 1-5 with 1 being Not at all helpful to 5 being Extremely helpful.

Table 3: Reported helpfulness of recorded lectures

\begin{tabular}{|l|c|c|}
\hline $\begin{array}{c}\text { Helpfulness of } \\
\text { recorded lectures }\end{array}$ & No. of students & Percent \\
\hline 1 (Not at all helpful) & 0 & 0 \\
\hline 2 & 2 & 9.1 \\
\hline 3 & 5 & 22.7 \\
\hline 4 & 13 & 59.1 \\
\hline $5($ Extremely helpful) & 2 & 9.1 \\
\hline Total & 22 & 100 \\
\hline
\end{tabular}

The mean score in relation to the perceived helpfulness of this technology was 3.7. Clearly, although students did not download the audio recordings of lectures frequently, those who did found it to be very helpful on the whole. Of those students who did access them, an overwhelming $95 \%$ of students listened to them from their home computer while only $5 \%$ listened to them while using a computer at their university campus.

The following comments, collected as part of the second questionnaire, were typical of the student experience in relation to the lecture recordings.

As I attended all lectures and tutorials I didn't feel the need to use the recordings as much as I would have if I was unable to attend. I think it's a great resource and for revision purposes, it's a really good idea.

I feel they would have been worthwhile had I not been able to make a lecture but this was not relevant to me.

Recordings are very good, as if I missed a lecture or had missed anything important in class it was great to have the opportunity to listen to it if I wanted to.

I have attended all the lectures and if I need to go back to the lecture I will read the lecture notes. I am more of a visual than an audio learner. 
Although most students reported that the recordings were easy to download and simple to use, not all students had the same experience.

My computer is incredibly slow so I find it frustrating trying to download the recordings.

I find it a time consuming process to download the audio at home, however, the computers at university seem to be a lot more efficient so I will endeavour to use them in the future.

If we could have had them in mp3 downloadable format it would be great.

I tried to but it was taking ages to download on my computer.

Although they didn't feel the need to download the recorded lectures, some students commented on the value of having them available just in case.

Because I attended all lectures in the semester, however, if I was unable to attend I would definitely have used the audio recordings.

I would have listened to them if for some reason I had been unable to attend a lecture. I think it is a great idea.

\section{Discussion}

\section{Student related}

This study does not support anecdotal concerns that Generation Y students will not attend lectures if they are provided online. The results would appear to indicate that this generation are indeed discriminatory about the quality of teaching on offer and that they do value the interactive nature of learning that should arise out of face to face teaching. It also supports the findings by Gosper et al. (2008) that students are strategic in the choices that they make as to what they will attend and the findings by Copley (2007) that students value the interactive nature of face to face teaching.

Although only a minority of students actually used the lecture recordings, those who did, found them to be of value. Flexible learning has many aspects of which pace, place and time are only some elements (Deakin University, 2008). The integration of this type of technology contributes in part to flexibility and recognises the diverse learning and personal needs of students without sacrificing other teaching and learning activities. Even those students who didn't access the recordings appeared to value their availability on a 'just in case' basis. These findings support similar findings by Scutter, Stupans, Sawyer and King (2010) who found that students did not generally substitute lectures with recordings, instead using them primarily for review purposes. Scutter et al. also found that students valued having recorded lectures available as a back up in case of unintended missed lectures. This 'just in case' perception by students appears to contribute to students' confidence in their ability to undertake their study thus adding value to their overall student experience.

As discussed by Kennedy et al. (2008), the use of this technology needs to be considered in the context of the need for equity of access to learning materials. The technology platforms used by universities to provide the latest in technological teaching advances need to take into account that not all students have high speed Internet access or the most up to date hardware systems. It is not appropriate to argue 
that universities can rely on students accessing these materials from university campuses. As emphasised by Kennedy (2008), if the commitment to flexible learning environments is genuine, access needs to be equitable and issues related to technical infrastructure outside of the university environment need to be considered. In addition, the availability of online lectures is in accordance with supporting students with a range of abilities and learning styles. Students benefit from being offered multiple opportunities to engage with the learning material without educators being fearful of the medium that they use to facilitate this engagement. With recommendations made in the recent Bradley Review of Australian Higher Education (DEEWR, 2008) to increase the equity and diversity participation rates of students in Australian universities, strategies that take account of a range of student abilities, needs and circumstances will become increasingly relevant.

\section{Teaching related}

Beyond the outcomes for students, there were other outcomes for the teaching staff that initially were not envisaged. An unintended outcome was the opportunity for the lecturer to listen to the recordings and reflect on lecturing style, points of emphasis and content. This provided a valuable opportunity to reflect on teaching practice as described by Kane et al. (2004). As the teaching staff became more confident over time that lecture attendance was not at risk, the unit coordinator became more confident with expanding the use of audio recordings and was able to be more responsive to the needs and requests of students for supplementary learning material in audio format, for example, assessment task information. This unintended outcome suggests that audio recordings could actually enhance the interpersonal relationship between teaching staff and students as described by Kane et al.

One question that a study of this kind raises is, was there greater attendance than in previous semesters due to the availability of recordings? Is it possible that students, who may otherwise have been predisposed to rely on recordings and not come to lectures, could actually be encouraged to attend after listening to the recordings and developing confidence in the subject knowledge and skills and personality of the teaching staff as per the model developed by Kane et al. (2004)? Further research that explores these sorts of questions would be valuable.

This study had a number of limitations. The class size was small and focused on one discipline. Research with larger groups and in various disciplines is necessary to further explore the role of audio recordings on students' experiences of learning and on attendance. It is also possible that the act of doing a head count in a relatively small class each week artificially raised the attendance levels. This was also noted by von Konsky, Ivins and Gribble (2009) in their study of information technology students, but as also noted by them, previous attendance patterns in the occupational therapy unit during this study were similar to those of previous semesters.

The student feedback scores on Deakin Universities' Student Evaluation of Teaching and Units questionnaire at the completion of this unit in some aspects was higher than previously recorded for the same subject. This feedback on its own does not capture the effectiveness of the teaching or the impact of lecture recordings on student learning outcomes (Biggs \& Tang, 2007). However, it does lend support to a view that providing lecture material online can contribute to, and enhance, the overall student experience. 
Student attendance is not a learning outcome. Therefore, in one sense it doesn't matter whether students attend lectures. What is important is whether learning is transformative and they achieve the intended learning outcomes determined for that unit of study. However, face to face teaching via lectures still remains a valued vehicle for interactive teaching and learning by both staff and students. It is, therefore, not inconsistent to value student attendance while at the same time providing online lecture recordings. Dillenbourg (2008) argues that "the borders between classroom/campus activities and distance activities are fading away" (p.127). In this context, technology enhanced learning is only one component of pedagogical strategies used by teaching staff. It adds value as a whole to the teaching and learning and student experience and allows teaching staff to further develop those attributes that promote excellent teaching as defined by Kane et al. (2004).

\section{Conclusion}

This study arose out of the subject coordinator reflecting on the potential impact of recording lectures and a desire to explore and identify what might be the outcomes. This study is as much about a reflective journey for the teaching staff as it is about the pros and cons of web based lecture technology and the experience of students through the introduction of this technology.

This research indicates that providing online recordings of lectures, does not in itself, lead to reduced attendance at lectures. It has provided evidence, as called for by Kennedy et al. (2008), that shows how pedagogically driven implementation of new technology can contribute to positive student outcomes and experience. Student attendance is more likely to be attributed to the interaction of teaching factors that engage students and contribute to their learning experience within that unit of study. Although only used by a minority of students in this study, providing this type of teaching technology can contribute to overall flexibility in educational environments that are inclusive and can better meet the needs of a diverse group of students. Recorded lectures, available online, does not equate with optional attendance at lectures but can be seen as an opportunity to add value to existing teaching and educational strategies. Educational technology needs to ensure that a broad cross section of students is able to use the technology at their place of choice in a way that is simple and easy to use. Downloading also needs to be as flexible as possible so that downloading to portable audio devices is easily performed.

This study explores an important issue, that is, the reality or perception of the impact of recorded lectures on student attendance. The findings support an emerging body of evidence that the use of lecture recordings does not impact on attendance at lectures (Scutter, Stupans, Sawyer \& King, 2010; von Konsky, Ivins \& Gribble, 2009). It also adds further corroboration to a trend towards blended learning environments (Concannon, Flynn \& Campbell, 2005; Craig, Wozniak, Hyde \& Burn, 2009) where the mode of study is less important than the need to engage students in their learning, using a variety of pedagogically valid strategies. When academic staff release themselves from the burden of worrying about attendance at lectures, they can become more responsive to the diverse learning and other needs of students and respond to them in pedagogically sound ways. The findings of this study have now been used by the occupational therapy program at Deakin University to implement routine 
recording of all lectures from 2009 onwards. This has occurred in the absence of any continuing anecdotal concern in relation to their impact on student attendance.

The provision of recorded lectures can enhance teaching and learning opportunities beyond mere convenience for those students who are otherwise unable to attend lectures. This study supports the view that they have the potential to enhance studentteacher relationships and contribute positively to overall student experience. Finally, the results of this study support a view that "if you could be replaced by a recorded lecture then why wouldn't you be?" It encourages teaching staff to consider the value added nature of this technology and challenges us to ensure that lectures are used not simply to convey information but to support the transformative nature of real learning.

\section{References}

Arhin, A. O. \& Cormier, E. (2007). Using deconstruction to educate Generation Y nursing students. Journal of Nursing Education, 46(12), 562-567.

Biggs, J. \& Tang, C. (2007). Teaching for quality learning at university (3rd ed). Berkshire: McGraw Hill, Society for Research into Higher Education \& Open University Press.

Bongey, S. B., Cizadlo, G. \& Kalnbach, L. (2006). Explorations in course-casting: Podcasts in higher education. Campus-Wide Information Systems, 23(5), 350-367.

Concannon, F., Flynn, A. \& Campbell, M. (2005). What campus-based students think about the quality and benefits of e-learning. British Journal of Educational Technology, 36(3), 501-512.

Copley, J. (2007). Audio and video podcasts of lectures for campus-based students: Production and evaluation of student use. Innovations in Education and Teaching International, 44(4), 387399.

Craig, P., Wozniak, H., Hyde, S. \& Burn, D. (2009). Student use of web based lecture technologies in blended learning: Do these reflect study patterns? In Same places, different spaces. Proceedings ascilite Auckland 2009. http: / / www.ascilite.org.au/conferences/auckland09/procs/craig.pdf

Deakin University (2008). Deakin University teaching and learning plan: 2008-2012. Burwood, Victoria: Deakin University.

Department of Employment, Education and Workplace Relations (2008). Review of Australian Higher Education: Final Report. Canberra: DEEWR. http:/ / www.deewr.gov.au/Higher Education/Review / Pages / ReviewofAustralianHigherEducationReport.aspx

Dillenbourg, P. (2008). Integrating technologies into educational ecosystems. Distance Education, 29(2), 127-140.

Gosper, M., Green, D., McNeill, M., Phillips, R., Preston, G. \& Woo, K. (2008). The impact of web-based lecture technologies on current and future practices in learning and teaching. Australian Learning and Teaching Council. [viewed 29 Jul 2009, verified 9 Apr 2010] http:/ / www.cpd.mq.edu.au/teaching/wblt/ overview.htm

Hove, M. C. \& Corcoran, K. J. (2008). If you post it, will they come? Lecture availability in introductory psychology. Teaching of Pyschology, 35(2), 91-95.

Kane, R., Sandretto, S. \& Heath, C. (2004). An investigation into excellent tertiary teaching: Emphasising reflective practice. Higher Education, 47, 283-310. 
Kennedy, G., Dalgarno, B., Bennett, S., Judd, T., Gray, K. \& Chang, R. (2008). Immigrants and natives: Investigating differences between staff and students' use of technology. In Hello! Where are you in the landscape of educational technology? Proceedings ascilite Melbourne 2008. http: / / www.ascilite.org.au/conferences/melbourne08/procs/kennedy.pdf

Kennedy, G. E., Judd, T. S., Churchward, A. \& Gray, K. (2008). First year students' experiences with technology: Are they really digital natives? Australasian Journal of Educational Technology, 24(1), 108-122. http: / / www.ascilite.org.au/ajet/ajet24/ kennedy.html

Lee, M. J. W. \& Chan, A. (2007). Pervasive, lifestyle-integrated mobile learning for distance learners: An analysis and unexpected results from a podcast study. Open Learning: The Journal of Open and Distance Learning, 22(3), 201-218.

McGarr, O. (2009). A review of podcasting in higher education: Its influence on the traditional lecture. Australasian Journal of Educational Technology, 25(3), 309-321. http: / / www.ascilite.org.au/ajet/ajet25/mcgarr.pdf

Nimon, S. (2007). Generation Y and higher education: The other Y2K. Journal of Institutional Research, 13(1), 24-41. http:/ / www.aair.org.au/jir/Nov07/GenY.pdf

Pardue, K. T. \& Morgan, P. (2008). Millenials considered: A new generation: New approaches, and implications for nursing education. Nursing Education Perspectives, 29(2), 74-79.

Pendergast, D. (2007). Teaching Y Generation. Journal of the HEIA, 14(3), 15-21.

Ramsden, P. (2003). Learning to teach in higher education (2nd ed). London: Routledge Falmer.

Scutter, S., Stupans, I., Sawyer, T. \& King, S. (2010). How do students use podcasts to support learning? Australasian Journal of Educational Technology, 26(2), 180-191. http:/ / www.ascilite.org.au/ajet/ajet26/scutter.html

Skiba, D. J. (2005). The millennials: Have they arrived at your school of nursing? Nursing Education Perspectives, 25(6), 370-371.

Taylor, M. Z. (2009). Podcast lectures as a primary teaching technology: Results of a one-year trial. Journal of Political Science Education, 5, 135-153.

von Konsky, B. R., Ivins, J. \& Gribble, S. J. (2009). Lecture attendance and web based lecture technologies: A comparison of student perceptions and usage patterns. Australasian Journal of Educational Technology, 25(4), 581-595.

http: / / www.ascilite.org.au/ajet/ajet25/vonkonsky.html

Williams, J. \& Fardon, M. (2007). Perpetual connectivity: Lecture recordings and portable media players. In ICT: Providing choices for learners and learning. Proceedings ascilite Singapore 2007. http:www.ascilite.org.au/conferences/singapore07/ procs/ williams-jo.pdf

Helen E. Larkin

School of Health and Social Development

Faculty of Health, Medicine, Nursing and Behavioural Sciences

Geelong Waterfront Campus, Deakin University, Geelong 3217, Australia

Email: helen.larkin@deakin.edu.au

An earlier version of this work was presented at HERDSA 2009 Conference, Darwin, 6-9 July. http:/ / conference.herdsa.org.au/2009/ concurrent04.html\#1819 